\title{
A high-throughput in vitro translation screen towards discovery of novel antimalarial protein translation inhibitors
}

Hella Baumann ${ }^{1 \star}$, Holly Matthews ${ }^{1}$, Mengqiao Li ${ }^{1}$, Jenny J. Hu${ }^{1}$, Keith R. Willison², and Jake Baum $^{1}$

${ }^{1}$ Department of Life Sciences, Imperial College London, London, UK.

${ }^{2}$ Department of Chemistry, Imperial College London, London, UK.

^ Current Address: 3i Intelligent Imaging Innovations Ltd, London, UK

\section{For correspondence:}

Professor Jake Baum. Department of Life Sciences, Imperial College London, Exhibition Road, South Kensington, London, SW7 2AZ, UK. Tel: +44 (0)207 5945420; Email:

jake.baum@imperial.ac.uk 


\section{ABSTRACT}

Drugs that target protein synthesis are well-validated for use as antimicrobials, yet specific high throughput (HTP) methods to screen for those targeting malaria are lacking. Here, we have developed a cell free in vitro translation (IVT) assay for the human malaria parasite, Plasmodium falciparum, which reconstitutes the native parasite protein translation machinery. Combining clarified IVT lysate with a click beetle luciferase reporter gene fused to untranslated regions of Pf histidine-rich proteins (hrp)-2 and 3, the HTP IVT assay accurately reports protein translation in a 384-well plate format using a standard spectrofluorometer. We validate the assay as effective in detecting compounds targeting the ribosome, ribosome co-factors (elongation factor 2) and cytosolic tRNA synthetases as well as its ability to find translation inhibitors in a blind screen using a high-density assay format amenable for high throughput. This demonstrates an ability to reconstitute the breadth of the parasite eukaryotic protein translation machinery in vitro and use it as a powerful platform for antimalarial drug discovery.

\section{INTRODUCTION}

Despite marked progress in reducing deaths from malaria, the disease remains a major cause of infant mortality in the developing world, with more than 500,000 estimated to die each year ${ }^{1,2}$. In the absence of a fully protective vaccine ${ }^{3}$, chemotherapeutics constitute the best available clinical tool to prevent or treat malaria disease. The most effective formulations, and standard of care recommended by the World Health Organization (WHO), are based on combination therapies with endoperoxides such as artesunate, artemisinin and artemether, referred to as artemisinin-based combination therapies (ACTs). However, like every clinical antimalarial to date, evidence is growing for the emergence of resistance to ACTs, specifically in South East Asia though not as yet in Africa ${ }^{4,5}$. To combat ACT resistance and prevent its potentially devastating spread to sub Saharan Africa new drugs are required with novel modes of action ${ }^{6}$. 
In recent years, cell-based screens have demonstrated great power in their capacity to discover compounds for development as next generation antimalarials. Notably, several of these screens have repeatedly found compounds with activity against malaria parasite protein synthesis ${ }^{7-9}$. Protein synthesis in the malaria parasite is an attractive target given its essential nature to parasite cell growth and development and the strong precedence for mRNA to protein translation as an antimicrobial target for bacterial infections ${ }^{10}$. Screening platforms to specifically identify compounds with similar activity against malaria would be a welcome addition to the antimalarial field to increase and differentiate the drug discovery pipeline. Towards this, two studies have devised formulation of a cell free in vitro translation (IVT) lysate ${ }^{11}$ and its development towards a luciferase reporter assay ${ }^{12}$. This provides a foundation from which inhibitors specific to protein synthesis in the most virulent human malaria parasite, Plasmodium falciparum. Whilst some compounds have been screened with this in mind, for example assaying of the Medicines for Malaria Venture Malaria Box ${ }^{12}$ (400 bioactive compounds with minimal human cytotoxicity profiles), the potential to translate such a platform to blind, high throughput (HTP) screening for compounds targeting the breadth of the protein translation machinery has not been fully realized. To address this, we sought to develop an optimized 384-well-plate assay for HTP screening, applicable to a conventional laboratory spectrofluorometer and validated for its robustness, replicability and capacity to find inhibitors of protein synthesis with diverse modes of action as demonstrated with known translation inhibitors.

\section{RESULTS AND DISCUSSION}

Building on recent efforts to devise a protein translation assay applicable to HTP screening, we first optimized a protocol for large scale, yet reduced budget, protein lysate production, compatible with protein translation. For the production of 3-8 $\mathrm{ml}$ lysate, up to 6 liters of a high parasitemia $P$. falciparum 3D7 culture were saponin-treated, with cytosolic extract released via nitrogen cavitation (see MATERIALS AND METHODS for details) (Figure 1A). This yielded on average a lysate with $1000-2000 \mu \mathrm{g} / \mathrm{mL}$ of total RNA as a measure for presence of ribosomal RNA and hence potential 
lysate activity. We next sought to develop a reporter system compatible with both a time course and endpoint plate-based assay with optimal signal to noise ratio but using reduced amounts of lysate. A parent vector, $\mathrm{pHLH}-1^{13}$, was used as the foundation for downstream expression plasmids, in which expression of Photinus pyralis firefly luciferase (Iuc) occurs under the control of flanking $P$. falciparum regulatory elements from the histidine rich proteins, namely the 5 ' promoter element from hrp3 and 3' untranslated region (UTR) from hrp2. To generate mRNA from this vector in vitro, a T7-terminator was introduced after this expression cassette using site-directed mutagenesis, generating the vector pHLH-T7term (referred to as pHLH here for simplicity).

The mRNA from cDNA was generated by a high yield in vitro transcription protocol previously established by Mureev et al ${ }^{14}$ prior to each assay. Supplementation of the lysate with energy and amino acids demonstrated efficient production of luciferase via $\mathrm{pHLH}$, detectable via luminescence from Oxyluciferin (Figure 1B) or by immunoblot (Figure 1C, asterisk). Adding the translation inhibitor Cycloheximide ( $\mathrm{CHX}$ ) reduced the amount of luciferase detected through luminescence of Oxyluciferin (Figure 1B) and in a western blot (Figure 1C), confirming the protein derives from in vitro translation. To validate the functionality of in vitro translation reagents and our workflow in a parallel Human embryonic kidney cells 293 (HEK) cell lysate, a further expression vector for luc (pIRES-Luc) was generated by cloning the luc expression cassette into a pT7CFE vector (see MATERIALS AND METHODS) generating an expression construct in which luciferase is flanked by a 5 ' internal ribosomal entry site (IRES) from encephalomyocarditis virus (EMCV) and a 3' polyadenyl tail (Supplementary Figure S1A).

Having validated in vitro translation (IVT) with the luciferase reporter system, we next attempted to optimize our platform for high throughput (HTP). Initial assays were scaled down from 50 to $20 \mu \mathrm{l}$ and performed in 384-well plates. Measurements from five endpoints (at 0-4h post assembly of lysate with energy, amino acids and mRNA), each set up in triplicate, following the incubation at $37^{\circ} \mathrm{C}$ with shaking every $30 \mathrm{~min}$ in a plate reader were taken. For each time-point the luciferase reaction buffer was added directly into the test wells 10 minutes prior to measurement. An increase 
bioRxiv preprint doi: https://doi.org/10.1101/248740; this version posted January 16,2018 . The copyright holder for this preprint (which was not certified by peer review) is the author/funder, who has granted bioRxiv a license to display the preprint in perpetuity. It is made available under aCC-BY-NC-ND 4.0 International license.

of detected luminescence demonstrated successful production of luciferase for at least $4 \mathrm{~h}$ (Figure 1D).

We next aimed to investigate whether the continuous monitoring of the IVT might provide further information about the dynamics of parasite translation and drug dynamics over time. To this end, we explored generation of an mRNA reporter construct using conventional $P$. pyralis firefly luciferase versus an alternative green bioluminescence reporter from the click beetle Pyrophorus plagiophthalamus CBG99 ${ }^{15}$. This was cloned into the $\mathrm{pHLH}$ construct replacing the luc expression cassette, generating a pH-CBG99-H expression vector with conserved flanking regulatory elements.

Customization of the luciferase reaction buffer (see MATERIALS AND METHODS), resulted in a 5fold increase of the signal to noise, which permitted a direct test between firefly and click beetle luciferase 5'hrp3 and 3'hrp2 flanked constructs to ascertain the optimal construct for signal intensity and continuous production of oxyluciferin, detectable with a plate reader. Of note, luminescence deriving from CBG99 mRNA, but not $L u c$, produced a signal detectable with a peak at about $2.5 \mathrm{~h}$ post-set up using our customized luciferase reaction buffer, added at the start of the reaction/incubation time (Figure 2A). This suggested that the click beetle luciferase is either more stably produced over time or its activity more stable than that of firefly luciferase under our IVT assay conditions ${ }^{15}$ (Figure 2A). We also explored the UTR-dependence of IVT using an alternative 5' promoter element from the $P$. falciparum erythrocyte binding antigen (eba)-175 (0.85 kb upstream of the ATG start site), a region previously validated for in vitro translation ${ }^{12}$ and the human IVT compatible UTR pIRES, generating pEBA175-CBG99-H and pIRES-CBG99 respectively (Figure $2 \mathrm{~B}$ ).

Comparison of the Pfhrp3 5' UTR with that from Pfeba-175, showed that whilst the eba-175 5'UTR is efficient in enabling IVT, as reported ${ }^{12}$, especially when compared to an EMCV IRES using parasite lysate, the hrp3 5'UTR is considerably more efficient and reliable (smaller variation of signal between single assays) under our IVT conditions (Figure 2B). Minimal translation was seen 
using the pIRES-CBG99 vector. pH-CBG99-H mRNA was therefore selected for all further screening using our customized reaction buffer, with peak luminescence seen around 120 minutes.

To validate the ability of the plate-based luminescence assay for drug screening, we tested its sensitivity to known translation inhibitors including $\mathrm{CHX}$ and emetine (EME) (both of which target the parasite ribosome ${ }^{16}$ ) and halofuginone (HF) a direct target of the cytoplasmic Plasmodium protein translation enzyme prolyl-tRNA synthetase ${ }^{17}$. Assayed in triplicate in the same experiment, each of these drugs showed inhibition of in vitro translation at nanomolar concentrations when measured at 2 hours (Figure 3A-C). Observed differences in the dynamics of the luminescence measured kinetically (time of onset, slope of increase, maximum and time-point at maximum measured luminescence) when assayed at $12 \mathrm{nM}$ (Figure 3D) showed that each drug exhibited different residual activity. Whilst we have not explored this here, this may indicate that the assay could potentially determine not only translation inhibition during a screen (as an endpoint) but could be developed to interrogate potential mechanisms of action (as derived from the kinetics of activity) and stability of the drug when the whole profile of the curve of luciferase signal is considered. Work is ongoing towards validation of the concept. The dose dependency curves for the three drugs $\mathrm{CHX}$, EME and HF (Figure $3 \mathrm{~A}-\mathrm{C}$ ) were broadly consistent with experimentally determined cell culture $\mathrm{IC}_{50}$ values for emetine dihydrochloride hydrate $( \pm 47 \mathrm{nM}){ }^{18}$ and $\mathrm{HF}( \pm 9 \mathrm{nM})$ 17 though less accurate for $\mathrm{CHX}$, which is extremely potent in cellular assays $\left(0.6 \mathrm{nM}^{19}\right)$. This verified the sensitivity of the IVT assay towards a least two classes of translation inhibitors, demonstrating its utility in detecting compounds beyond those targeting only the ribosome.

The Medicines for Malaria Venture (MMV) Malaria Box is a collection of 400 compounds representing families of structures identified as having activity against $P$. falciparum ${ }^{20}$. Some of these were recently shown to affect parasite in vitro translation ${ }^{12}$. Leading on from this we sought to validate the previously reported activity of candidate compounds compared to a third class of translation inhibitor, DDD107498, a current antimalarial in preclinical development that targets parasite protein translation via the translation elongation factor $2(\mathrm{eEF} 2)^{8}$. Contrary to published findings ${ }^{12}$, measurement at 120 minutes did not show any substantial translation inhibition activity 
from the top $8 \mathrm{MMV}$ compounds previously identified (Figure 4A, highlighted (blue labels) besides 8 further random MMV compounds (black)). Where activity was seen it was inconsistent between replicate runs (e.g. compound MMV006767, Figure 4A). It is unclear whether the poor activity seen in our screen is the result of use of a different parasite strain in our assay (3D7 versus W2mef), the buffer conditions used or differences in the 5'UTR. The validated translation inhibitor DDD107498, however, showed potent activity leading to a $73.5 \%$ inhibition of translation in our assay (Figure 4A). This further validates the breadth of activity detectable in our IVT assay, whilst suggesting that the Malaria Box is unlikely to have a potent translation inhibitor in its collection.

Finally, having verified the activity of our IVT platform for screening, we sought to undertake a blind HTP screen of untested compounds as validation for future screening of entire compound libraries. A proof-of-concept screen of 247 developmental antimicrobials in a 384-well plate format measured at 120 minutes was undertaken, with compounds selected from a \pm 2 million compound library (courtesy of GlaxoSmithKline) as having potential antimicrobial properties. Activity was generally very low with each compound tested, with few showing up to $30 \%$ inhibition of parasite protein translation (standardized for internal negative [DMSO] or positive [HF] controls) and none giving consistent inhibition across replicate plates (see Supplementary Data Table 1). One exception was a single compound identified as effectively reducing translation by $\pm 99 \%$ (Figure 4B, compound A14). On un-blinding, this compound was revealed to be Puromycin, a drug known to inhibit protein translation, which has been previously shown to have nanomolar activity against $P$. falciparum ${ }^{21}$.

In conclusion, we have optimized a cell free lysate for HTP IVT that reconstitutes the complete parasite translation machinery. The IVT assay is validated as effective in detecting compounds that inhibit ribosome activity directly (Emetine, Cycloheximide and Puromycin), ribosome co-factors (e.g. the recently identified compound DDD107498, targeting elongation factor elongation factor 2 (eEF2)) and tRNA synthetases (Halofuginone). We also describe the first blind screen for translation inhibitors using a small library of compounds enriched for anti-microbial activity, which although unable to find a new antimalarial hit successfully, found the only known translation 
inhibitor (Puromycin) in a blinded array of 247 compounds. This validates our HTP IVT platform, with potential to scale to several thousand compounds per week, for its ability to screen novel drug libraries for hits targeting malaria parasite protein translation. In continuous-read format, the IVT platform has the potential of providing immediate insights into the characteristics of each potential hit, where drugs of different mechanism may be revealed through the interrogation of their kinetic traces - a concept we are currently exploring. We believe the HTP IVT platform will provide a powerful addition to the antimalarial drug discovery pipeline.

\section{MATERIALS AND METHODS}

\section{Vectors for in vitro mRNA production}

Final plasmid sequences are available upon request. Maps are given in Supplementary Figure S1B.

pHLH-T7term. For efficient in vitro mRNA transcription, a T7 phage polymerase terminator region was introduced into the $\mathrm{pHLH}-1$ downstream the 3' hrp2-UTR by site directed mutagenesis (forward primer: CGCGCTTGGCGAATCATGGTCA, revers primer: GCTAGTTATTGCTCAGCGGCAATTAACCCTCACTAAAGGGAACAAAAG).

pH-CBG99-H. The firefly luciferase (IUc) was replaced in the pHLH-T7term with the click beetle luciferase gene cbg99. Briefly, the cbg99 expression cassette was PCR amplified from pCBG99 (Promega) using the forward primer

ITAATACAGTTATTTTAAAAAACCATGGTGAAGCGTGAGAAAAATGTCATC and reverse primer ITTTTAATCTATTATTAAATAAGCTTCTAACCGCCGGCCTTCTCCAA (homology regions are underlined) and pHLH-1 was restricted at its Nsil and Hindlll sites prior to enzyme-dependent assembly cloning ${ }^{22}$.

pEBA-CBG99-H. An 850 bp long region directly upstream of the EBA-175 start codon was PCR amplified from genomic DNA from 3D7 parasites using the forward primer 
CGACGTTGTAAAACGACGGCCAGTGAATTCGGAAGAAACAAGTGGTGTTCTAAAATATAATTA

GC and the reverse primer

GATGACATTTTTCTCACGCTTCACCATTGTATGCACATTGAATATATTTATATGTTATTATC, the cbg99 expression cassette was amplified from pCBG99 (Promega) using the forward primer ATGGTGAAGCGTGAGAAAAATGTCATC and reverse primer

ITTTTAATCTATTATTAAATAAGCTTCTAACCGCCGGCCTTCTCCAA (homology regions are underlined) and pHLH-1 was restricted at its EcoRI and Hindlll sites prior to enzyme-dependent assembly cloning.

pIRES-Luc. The luc expression cassette from pHLH-1 was amplified by PCR using the forward primer, CACGATGATAATATGGCCACCATGCATGAAGACGCCAAAAACATAAAG and the reverse primer TCAGTGGTGGTGGTGGTGGTGCTCCAATTTGGACTTTCCGCCCTTCTTG (homology regions are underlined) and introduced into a pT7CFE vector (Thermo Fisher Scientific) using the restriction sites Ndel and Xhol and enzyme-dependent assembly cloning, resulting in pT7CFE-luc.

pIRES-CBG99. The cbg99 expression cassette from pCBG99 was amplified by PCR using the forward primer GAAAAACACGATGATAATATGGCCACCATGGTGAAGCGTGAGAAAAATGT, and the reverse primer CAGTGGTGGTGGTGGTGGTGCTCGAGACCGCCGGCCTTCTCCAACAAT (homology regions are underlined) and introduced into a pT7CFE vector (Thermo Fisher Scientific) using the restriction sites Ndel and Xhol and enzyme-dependent assembly cloning, resulting in pT7CFE-cbg99.

Plasmodium falciparum large scale culture. To prepare parasites for lysate production, 3-5 L of asexual $P$. falciparum parasites (3D7 strain) were grown in $225 \mathrm{~cm}^{2}$ flasks containing $300 \mathrm{~mL}$ complete RPMI (RPMI 1640 media supplemented with 25 mM HEPES (pH 7.4), 0.25\% (w/v) sodium bicarbonate, $50 \mu \mathrm{g} / \mathrm{ml}$ hypoxanthine (Sigma-Aldrich), $25 \mathrm{ug} / \mathrm{l}$ gentamycin and $0.5 \%(\mathrm{w} / \mathrm{v}$ ) Albumax II (Life Technologies)). Culture flasks were maintained at $2 \%$ hematocrit blood (UK NHS Blood Transfusion Service), individually filled with 'Malaria gas' (3\% (vol/vol) $\mathrm{O}_{2} / 5 \% \mathrm{CO}_{2} / 92 \% \mathrm{~N}_{2}$ (BOC Special Gases)) and stored in a $37^{\circ} \mathrm{C}$ incubator. Prior to seeding into large-scale flasks at 
$2 \%$ ring-stage parasitemia, parasites were synchronized with $5 \%$ sorbitol (Sigma Aldrich) to achieve high synchronicity ${ }^{23}$. Media was exchanged daily until the culture reached $10-20 \%$ parasitemia. Cells were harvested at late trophozoite stage (approximately $30 \mathrm{~h}$ post-invasion) by centrifugation for $5 \mathrm{~min}$ at $800 \times g$ at room temperature (Eppendorf). Red blood cells were lysed in pellet wash buffer (PWB) containing $45 \mathrm{mM}$ HEPES pH 7.4, $2 \mathrm{mM} \mathrm{Mg(OAc})_{2}, 100 \mathrm{mM} \mathrm{KOAc,} 250$ mM Sucrose, 2 mM DTT, $20 \mathrm{U}$ human placental RNase Inhibitor (2520), and $15 \mu \mathrm{M}$ Leupeptin (L2884) supplemented with $0.075 \%(\mathrm{w} / \mathrm{v})$ saponin (Sigma-Aldrich) for $5 \mathrm{~min}$ at room temperature. Lysed pellets were centrifuged at $4{ }^{\circ} \mathrm{C} 2800 \times g$ for $10 \mathrm{~min}$ and washed with ice-cold PWB. Wash steps were repeated until supernatant lost its red stain. Parasite pellets were either shock frozen and stored at $-80^{\circ} \mathrm{C}$ for no longer than 1 month or immediately used for lysate production.

Production of Plasmodium falciparum IVT lysate. Washed pellets were re-suspended in 1-1.5 x pellet volumes of PWB supplemented with 1× EGTA-free protease inhibitor cocktail (Roche) and filled into a $45 \mathrm{~mL}$ pre-chilled nitrogen cavitation chamber (Parr Instrument Company) and incubated on ice at $1500 \mathrm{psi}$ for $45 \mathrm{~min}$. After release from the chamber the crude lysate was clarified by differential centrifugation, $15 \mathrm{~min}$ at $10,000 \times \mathrm{g}$ followed by $15 \mathrm{~min}$ at $30,000 \times \mathrm{g}$ at $4^{\circ} \mathrm{C}$. As a measure for activity, the RNA content of the supernatant was checked using nanospectroscopy (Thermo Fisher Scientific). Lysates with a concentration above $1000 \mathrm{ng} / \mu \mathrm{l}$ were stored in aliquots of $100 \mu \mathrm{l}$ at $-80^{\circ} \mathrm{C}$.

Continuous in vitro translation and luciferase assay. For each IVT assay, several aliquots of different $P$. falciparum asexual stage lysate harvests were pooled to ensure consistency of activity. For dynamic assays validated with test drugs (Cycloheximide, Emetine and Halofuginone, SigmaAldrich) and screens, each reaction was assembled to a final volume of $20 \mu$. Each assay contained $25 \%$ lysate, $5 \%$ Amino acids (for final concentration $200 \mu \mathrm{M}$ each, Sigma-Aldrich, stocks prepared according to Sun et al. ${ }^{24}$ ), $5 \%$ energy and energy recovery system (final concentrations: 1.5 mM ATP, $0.15 \mathrm{mM}$ GTP, $40 \mathrm{U} / \mathrm{ml}$ Creatine kinase (Sigma-Aldrich) and $4 \mathrm{mM}$ Creatine phosphate (Fisher Scientific) in 40 mM HEPES), 5\% additional components (final concentrations: 2\% (w/w) PEG3000 (Sigma-Aldrich), 1 mM Spermidine (Sigma-Aldrich), $0.5 \mathrm{mM}$ Folinic acid 
(Sigma-Aldrich), $200 \mu \mathrm{M}$ Cystine and15 $\mu \mathrm{M}$ Leupeptin), 5\% of supplemental HEPES, KOAC, $\mathrm{Mg}(\mathrm{OAC})_{2}$, DTT, RNase Inhibitor to equalize concentrations with PWB buffer, 4.5\% 5'HRP3CBG99-3'HRP2 mRNA (3500 ng/ $\mu$ l) in vitro transcribed from pH-CBG99-H (following ${ }^{14}$ ), 0.5\% DMSO or Drug dissolved in DMSO and, finally, $50 \%$ customized luciferase reaction buffer (45 mM HEPES (pH 7.4), 1 mM MgCl 2,1 mM ATP, 5 mM DTT, 1\% (v/v) Triton-X, 10 mg/ml BSA, $1 \mathrm{x}$ Reaction enhancer (Thermo Fisher Scientific), $1 \mathrm{mg} / \mathrm{ml} \mathrm{D-Luciferin).} \mathrm{Provision} \mathrm{of} \mathrm{mRNA} \mathrm{(following}$ ${ }^{14}$ ) involved incubation of 50-70 $\mathrm{ng} / \mu \mathrm{l}$ of cDNA in a customized transcription buffer (40 mM HEPES, $\mathrm{pH}$ 7.4, $18 \mathrm{mM} \mathrm{Mg}(\mathrm{OAc})_{2}, 5 \mathrm{mM}$ each rNTPs (GE Healthcare Life Sciences), $2 \mathrm{mM}$ Spermidine (Sigma), $40 \mathrm{mM} \mathrm{DTT,} 0.0025 \mathrm{U} / \mu \mathrm{l}$ Inorganic Phosphatase (Fermentas), $3 \mathrm{U} / \mu \mathrm{l}$ human placental RNase Inhibitor (Sigma), $10 \mathrm{U} / \mu \mathrm{IT7}-\mathrm{RNA}$ Polymerase) for $100 \mathrm{~min}$ at $37^{\circ} \mathrm{C} .0 .5 \mu \mathrm{l}$ DNasel (Fermentas) was added for the last $20 \mathrm{~min}$. After dilution 1:1 (v/v) with RNase-free water, the mRNA was precipitated by addition of $0.5 \times$ initial volume of $8 \mathrm{M} \mathrm{LiCl}$ followed by 30 min incubation on ice and subsequent centrifugation (20 min, Eppendorf 5424, full speed). The mRNA pellet was dissolved and precipitated again in presence of $0.3 \mathrm{M} \mathrm{NH} 4 \mathrm{OAc}$ with $2.5 \mathrm{x}$ volumes of absolute ethanol while kept at $-80^{\circ} \mathrm{C}$ for $30 \mathrm{~min}$. The mixture was spun at full speed for 20 min (Eppendorf 5424), the mRNA pellet washed with $70 \%$ ethanol and dissolved in an appropriate volume of RNase-free water to a concentration of $3500 \mathrm{ng} / \mu \mathrm{l}$ shortly before experiments.

IVT reactions were carried out in low volume 384-well plates (Coring \#3820 or Greiner BioOne \#784101). DMSO and drugs were dispensed prior to assay assembly and plates were with sealed and stored at $-20^{\circ} \mathrm{C}$ for up to 2 weeks. IVT components were dispensed using an ECHO 525 acoustic dispersion system (SynbiCITE, Imperial College London, UK) and incubated on drug for $15 \mathrm{~min}$ prior to addition of customized luciferase reaction buffer. Plates were then immediately transferred into a plate reader (Labtech, Tecan M200 Pro) and detection of luminescence in each well was carried out every 10 min over $5 \mathrm{~h}$, while the sample was incubated at $37^{\circ} \mathrm{C}$ and shaken before every time-point.

For initial validation of in vitro translation of firefly luciferase and end-point measurements, assays were run in HEK cell and Plasmodium falciparum lysate $50 \mu$ total assay volume containing $1 \%$ 
bioRxiv preprint doi: https://doi.org/10.1101/248740; this version posted January 16,2018 . The copyright holder for this preprint (which was not certified by peer review) is the author/funder, who has granted bioRxiv a license to display the preprint in perpetuity. It is made available under aCC-BY-NC-ND 4.0 International license.

DMSO and either no mRNA or 5'EMCV IRES-Luc-3'Poly(A) mRNA in vitro transcribed from pT7CFE-Luc or 5'HRP3-Luc-3'HRP2 mRNA in vitro transcribed from pHLH-T7term respectively (Supplementary Figure S1A, Figure $1 \mathrm{~B}-\mathrm{C})$. Assays were run over night $(15 \mathrm{~h})$ at $37^{\circ} \mathrm{C}$ with shaking every 30 min. Purchased luciferase reaction solution (Thermo Fisher Scientific) was added (1:1 v/v) using a multistep pipette (Eppendorf) 10 minutes before detection in the plate reader. For endpoint-assays in 384-well plates, the reaction volume was scaled down to $20 \mu$ lysate measurements were taken every hour over $4 \mathrm{~h}$. Purchased luciferase reaction solution (Thermo Fisher Scientific) was added (1:1 v/v) using a multistep pipette (Eppendorf) 10 minutes before detection in the plate reader (Figure 1D).

To optimize continuous assay conditions, reactions were performed with either no mRNA or the following in vitro transcribed mRNAs: 5'HRP3-Luc-3'HRP2 from pHLH-T7term or 5'HRP3-CBG993'HRP2 from pH-CGB99-H. Customised luciferase reaction buffer (described above) was added using a multistep pipette immediately prior to the incubation at $37^{\circ} \mathrm{C}$ and start of measurement in the plate reader. Luminescence in each well was detected at time points $0 \mathrm{~h}, 1 \mathrm{~h}, 3 \mathrm{~h}, 4 \mathrm{~h}, 5 \mathrm{~h}, 6 \mathrm{~h}$ and $7 \mathrm{~h}$ (Figure 2A). To optimize 5'UTRs, reactions were performed with the following in vitro transcribed mRNAs: 5'HRP3-CBG99-3'HRP2 from pH-CBG99-H, 5'EBA175(0.8)-CBG99-3'HRP2 from pEBA-CBG99-H or 5'EMCV IRES-CBG99-3'Poly(A) mRNA in vitro transcribed from pT7CFECBG99 (Figure 2B).

Data Analysis. Results for each screen (Figure 4) were from either two, internal triplicated (MMV drugs) or three independent (antimicrobials) assays containing DMSO and HF as negative and positive controls respectively or drugs at varying concentrations. Inhibition (I [\%]) was calculated from values at the time-point of maximum luminescence of the DMSO control (90-120 min after incubation start $)$ normalized to the average control's values at this time-point as: $I=100-\left(\left(V_{d^{-}}\right.\right.$ $\left.\left.\mu_{\mathrm{p}}\right) /\left(\mu_{\mathrm{n}}-\mu_{\mathrm{p}}\right)^{*} 100\right)$, where $\mathrm{V}$ is the measured value, $\mu$ the is the mean, $\mathrm{d}$ the drug, $\mathrm{p}$ the positive controls and $\mathrm{n}$ the negative controls. Robustness ( $\mathrm{Z}^{\prime}$ value) of plate based screens was calculated from the DMSO and HF controls using the formula Z' $=1-\left(\left(3 \times\left(\sigma+\sigma_{n}\right)\right) /\left(\left|\mu_{p}-\mu_{n}\right|\right)\right)$, with $\sigma$ as the standard deviation. Raw data of the tests are available upon request. 
HEK cell large scale culture. 0.5-1 L unmodified FreeStyle 293-F cells (Thermo Fisher Scientific) were grown in FreeStyle 293 Expression Medium in suspension to a density of $2 \times 10^{6} \mathrm{cells} / \mathrm{ml}$. Cells were pelleted for $15 \mathrm{~min}$ at $2.500 \mathrm{x} \mathrm{g,} 4^{\circ} \mathrm{C}$ (Beckman Avanti centrifuge, JLA 10.500 Rotor) and washed by re-suspension in $5 \mathrm{x}$ cell pellet volume PWB. After a subsequent centrifugation for $15 \mathrm{~min}$ at $2.500 \times \mathrm{g}, 4^{\circ} \mathrm{C}$ (Eppendorf), cell pellets were either shock frozen and stored at $-80^{\circ} \mathrm{C}$ for no longer than 6 months or immediately used for lysate production. Production of the IVT lysate, in vitro translation and luciferase assay were performed as described above with the exception that the mRNA for human IVT was transcribed from a pT7CFE vector (Thermo Fisher Scientific) so that the firefly luciferase was flanked by a EMCV IRES at the 5' UTR and a poly adenyl tail.

Immunoblots. SDS-PAGE gels were run with $10 \mu \mathrm{l}$ IVT lysate after $15 \mathrm{~h}$ incubation, incubated with $2 \mu \mathrm{l}$ reducing sample buffer $\left(95^{\circ} \mathrm{C}, 5 \mathrm{~min}\right)$, at $160 \mathrm{~V}$ for $45 \mathrm{~min}$. Proteins were blotted onto a nitrocellulose membrane (Life Technologies) using an iBlot (Life Technologies) at program 0. The membrane was subsequently incubated in PBS containing 5\% (w/v) skimmed milk powder for $1 \mathrm{~h}$, before incubated with a mouse monoclonal anti-firefly luciferase antibody (Thermo Fisher Scientific) 1:2000 in PBS at $4^{\circ} \mathrm{C}$ overnight. After washing with PBS containing 1\% (v/v) Tween-20, the membranes were incubated in horse radish peroxidase-conjugated anti-mouse (Sigma-Aldrich) antibody for $1 \mathrm{~h}$ at room temperature before washed and incubated in Amersham ECL Western Blotting reagent (GE Healthcare Life Sciences). Chemiluminescence was detected by exposing films (Carestream Kodak BioMax, Sigma-Aldrich) for $10 \mathrm{~s}$ and developing in an automated developer.

\section{ACKNOWLEDGMENTS}

We thank Vida Ahyong and Joseph Derisi (UCSF) for generously sharing pre-publication data and methodological insights into Plasmodium in vitro translation. We thank Fernando Sanchez-Roman Teran (Imperial College London) for help with optimization of Plasmodium falciparum large-scale culture, Maria G. Gomez-Lorenzo, Francisco Javier Gamo and Luis Ballell-Pages (GlaxoSmithKline) and Michael Delves (Imperial College London) for providing test drugs, experimental advice and productive discussions regarding HTP screening and data analysis. We 
bioRxiv preprint doi: https://doi.org/10.1101/248740; this version posted January 16, 2018 . The copyright holder for this preprint (which was not certified by peer review) is the author/funder, who has granted bioRxiv a license to display the preprint in perpetuity. It is made available under aCC-BY-NC-ND 4.0 International license.

thank David McClymont (SynbiCITE) for thoughtful discussions about assay design and providing access to the $\mathrm{ECHO} 252$ system for lysate printing. We also thank Niklas Rehmert and Marko Storch (Imperial College London) for assistance in the early stages of this project and the UK NHS Blood Transfusion Service for generous provision of red blood cells. The research was directly supported by the Imperial Confidence in Concept Scheme, NIHR Imperial Biomedical Research Centre / Imperial Innovations Therapeutic Primer Fund \& NIHR BRC at the Royal Marsden and the Institute of Cancer Research Funds 2014 (P51477) (J.B. \& K.R.W.) and a Wellcome Pathfinder Award (105686) (J.B.). J.B. is supported by a Wellcome Investigator Award (100993/Z/13/Z).

\section{AUTHORSHIP CONTRIBUTIONS}

H.B., H.M., K.R.W., and J.B. designed all experiments; H.B., H.M., M.L, and J.J.H. performed experiments; All authors contributed to manuscript preparation; H.B. and J.B. wrote the manuscript.

\section{CONFLICT OF INTEREST DISCLOSURES}

The authors declare no competing financial interests.

\section{REFERENCES}

1 Bhatt, S. et al. The effect of malaria control on Plasmodium falciparum in Africa between 2000 and 2015. Nature 526, 207-211, doi:10.1038/nature15535 (2015).

2 WHO. World Malaria Report. (WHO, 2016).

3 Partnership, R. C. T. Efficacy and safety of RTS,S/AS01 malaria vaccine with or without a booster dose in infants and children in Africa: final results of a phase 3, individually randomised, controlled trial. Lancet 386, 31-45, doi:10.1016/S0140-6736(15)60721-8 (2015).

4 Ashley, E. A. et al. Spread of artemisinin resistance in Plasmodium falciparum malaria. $N$ Engl J Med 371, 411-423, doi:10.1056/NEJMoa1314981 (2014).

5 Menard, D. et al. A Worldwide Map of Plasmodium falciparum K13-Propeller Polymorphisms. N Engl J Med 374, 2453-2464, doi:10.1056/NEJMoa1513137 (2016).

6 Wells, T. N., Hooft van Huijsduijnen, R. \& Van Voorhis, W. C. Malaria medicines: a glass half full? Nat Rev Drug Discov 14, 424-442, doi:10.1038/nrd4573 (2015).

7 Gamo, F.-J. et al. Thousands of chemical starting points for antimalarial lead identification. Nature 465, 305-310, doi:10.1038/nature09107 (2010).

8 Baragana, B. et al. A novel multiple-stage antimalarial agent that inhibits protein synthesis. Nature 522, 315-320, doi:10.1038/nature14451 (2015).

9 Kato, N. et al. Diversity-oriented synthesis yields novel multistage antimalarial inhibitors. Nature 538, 344-349, doi:10.1038/nature19804 (2016). 
10 Wilson, D. N. Ribosome-targeting antibiotics and mechanisms of bacterial resistance. Nat Rev Microbiol 12, 35-48, doi:10.1038/nrmicro3155 (2014).

11 Ferreras, A., Triana, L., Correia, H., Sanchez, E. \& Herrera, F. An in vitro system from Plasmodium falciparum active in endogenous mRNA translation. Mem Inst Oswaldo Cruz 95, 231-235 (2000).

12 Ahyong, V. et al. Identification of Plasmodium falciparum specific translation inhibitors from the MMV Malaria Box using a high throughput in vitro translation screen. Malar J 15, 173, doi:10.1186/s12936-016-1231-8 (2016).

13 Wu, Y., Sifri, C. D., Lei, H. H., Su, X. Z. \& Wellems, T. E. Transfection of Plasmodium falciparum within human red blood cells. Proc Natl Acad Sci U S A 92, 973-977 (1995).

14 Mureev, S., Kovtun, O., Nguyen, U. T. \& Alexandrov, K. Species-independent translational leaders facilitate cell-free expression. Nat Biotechnol 27, 747-752, doi:10.1038/nbt.1556 (2009).

15 Wood, K. V., Lam, Y. A. \& McElroy, W. D. Introduction to beetle luciferases and their applications. J Biolumin Chemilumin 4, 289-301, doi:10.1002/bio.1170040141 (1989). Wong, W. et al. Cryo-EM structure of the Plasmodium falciparum $80 \mathrm{~S}$ ribosome bound to the anti-protozoan drug emetine. eLife, e03080, doi:10.7554/eLife.03080 (2014).

17 Jain, V. et al. Structure of Prolyl-tRNA Synthetase-Halofuginone Complex Provides Basis for Development of Drugs against Malaria and Toxoplasmosis. Structure 23, 819-829, doi:10.1016/j.str.2015.02.011 (2015).

18 Matthews, H., Usman-Idris, M., Khan, F., Read, M. \& Nirmalan, N. Drug repositioning as a route to anti-malarial drug discovery: preliminary investigation of the in vitro anti-malarial efficacy of emetine dihydrochloride hydrate. Malar J 12, 359, doi:10.1186/1475-2875-12359 (2013).

19 Gershon, P. D. \& Howells, R. E. Mitochondrial protein synthesis in Plasmodium falciparum. Mol Biochem Parasitol 18, 37-43 (1986).

20 Van Voorhis, W. C. et al. Open Source Drug Discovery with the Malaria Box Compound Collection for Neglected Diseases and Beyond. PLoS Pathog 12, e1005763, doi:10.1371/journal.ppat.1005763 (2016).

21 Mamoun, C. B., Gluzman, I. Y., Goyard, S., Beverley, S. M. \& Goldberg, D. E. A set of independent selectable markers for transfection of the human malaria parasite Plasmodium falciparum. Proc Natl Acad Sci U S A 96, 8716-8720 (1999).

22 Gibson, D. G. et al. Enzymatic assembly of DNA molecules up to several hundred kilobases. Nat Methods 6, 343-345, doi:10.1038/nmeth.1318 (2009).

23 Lambros, C. \& Vanderberg, J. P. Synchronization of Plasmodium falciparum erythrocytic stages in culture. J Parasitol 65, 418-420 (1979).

24 Sun, Z. Z. et al. Protocols for implementing an Escherichia coli based TX-TL cell-free expression system for synthetic biology. J Vis Exp, e50762, doi:10.3791/50762 (2013).

\section{FIGURE LEGENDS}

Figure 1. Parasite in vitro translation of firefly luciferase (luc). A) Schematic of IVT lysate

production and assay. B) Bar diagram demonstrating the in vitro translation of luc as detected from luminescence after 15 hours incubation. Results are shown as averages of duplicate assays with either DMSO or $1 \mu \mathrm{M}$ Cycloheximide in DMSO. Error bars show standard deviation. C)

Demonstration of luc expression after 15 hours with western blot. Lysates merged after duplicate assay with either DMSO or $1 \mu \mathrm{M}$ Cycloheximide in DMSO. Asterisk indicates supposed run length 
of firefly luciferase D) In vitro Translation of luc over time as measured by luminescence. The graph shows detected averages of triplicate assays with DMSO at indicated time points when luciferase reaction mix was added. Error bars indicate standard deviation.

Figure 2. Optimization of the mRNA construct for continuous IVT. A) A time-course comparison of luminescence from luc and cbg99 translated in lysate containing the luciferase reaction buffer from start of incubation to test stability of components in each assay. Left, schematics of the mRNA constructs used for luc and cbg99 flanked by the histidine rich protein (hrp) 3 5' UTR and hrp 2 3' UTR. Right, the graph shows detected averages of triplicate assays with DMSO at indicated time points after start of the IVT assay/incubation (time point $0 \mathrm{~h}$ ). Error bars indicate standard deviation. B) Comparison of in vitro translation levels of cbg99 depending on the flanking UTRs. Left, schematics of the mRNA constructs used for cbg99 flaked by either the histidine rich protein (hrp) 5' and 3' UTR, by a EBA-175 5' UTR and hrp 3'UTR or the EMCV IRES 5' UTR and a polyadenyl tail. Right, the graph shows detected averages of triplicate assays with DMSO at indicated time points after start of the IVT assay/incubation (time point $0 \mathrm{~h}$ ). Error bars indicate standard deviation.

Figure 3. IVT Assay validation using known protein translation drugs. Bar charts show concentration-dependent inhibition of translation in presence of Cycloheximide, $\mathrm{CHX}(\mathbf{A})$, Emetine, EME (B) and Halofuginone, HF (C) respectively. Values arise from triplicate assays using a 12point titration in the range of $50 \mu \mathrm{M}$ to $0.005 \mu \mathrm{M}$ measured at 120 minutes. D) Graph shows dynamic luminescence over time from triplicate assays containing either DMSO or drug at $12 \mathrm{nM}$. Error bars indicate standard deviation.

Figure 4. IVT Assay test of drug libraries. A) Screen of a selection of Medicines for Malaria Venture (MMV) Malaria box drugs compared with recently identified translation inhibitor DDD $107498^{8}$. Bar graph shows the percentage of inhibition as mean of both of 2 independent assays (each in triplicate) with either $1 \mu \mathrm{M}$ (final concentration) drug dissolved in DMSO measured at 120 minutes. Error bars indicate Standard Deviation. Drugs previously predicted to be active are labelled in blue. Blue horizontal lines indicate a threshold (50\%) for drugs considered as hit. B) 
Blind screen of 247 selected compounds (enriched for potential antimicrobial activity) in HTP IVT assay in a 384-well plate format. Results shown in the bar graph are mean percentage inhibition from 3 independent assays (in singular form) from a 384-well plate containing $5 \mu \mathrm{M}$ (final concentration) drug dissolved in DMSO measured at 120 minutes. Blue horizontal lines indicate a threshold (50\%) for drugs considered as hits. For raw data values see Supplementary Data Table 1. 
bioRxiv preprint doi: https://doi.org/10.1101/248740; this version posted January 16,2018 . The copyright holder for this preprint (which was not certified by peer review) is the author/funder, who has granted bioRxiv a license to display the preprint in perpetuity. It is made available under aCC-BY-NC-ND 4.0 International license.

Baumann et al - Figure 1.

A

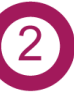

3-5 L 3D7 culture in Flasks Late Troph stage $\sim 15 \%$ parasitemia

Saponin lysis

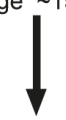

3-5 $\mathrm{ml} 3 \mathrm{D} 7$ cell pellet Washed in PWB until clear

Resuspension in $1 x$ pellet vol. $P W B \mid N 2$ cavitation

\section{5-10 $\mathrm{ml}$ 3D7 cell lysate} Washed until clear

Differential Centrifugation (15‘ 10k x g, 15‘30k x g)

3-5 $\mathrm{ml}$ 3D7 IVT lysate S30 fraction at $\sim 1500 \mathrm{ng} / \mu \mathrm{l}$ RNA

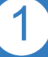

DMSO or Drug (0.5\%) dispensed prior to assay

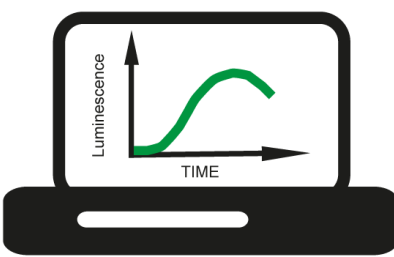

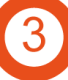
Energy,

Additive Reagents

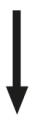

Each as 10X solutions; Adjusted to PWB concentrations

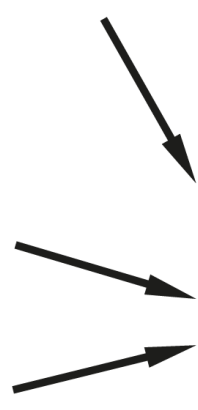

Plate Reader

Luciferase

Added after 15 min at RT

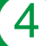

mRNA

In vitro transcribed from $\mathrm{CDNA}$

Reaction Buffer

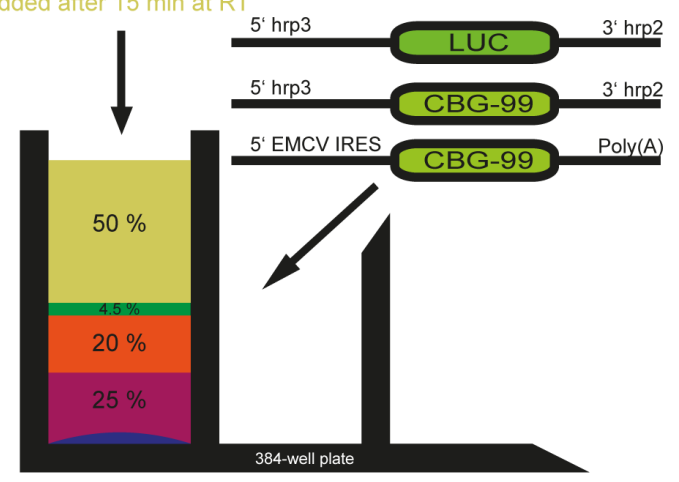

$5 \mathrm{~h}$ at $37^{\circ} \mathrm{C}$

shaking and detection every $10 \mathrm{~min}$
B

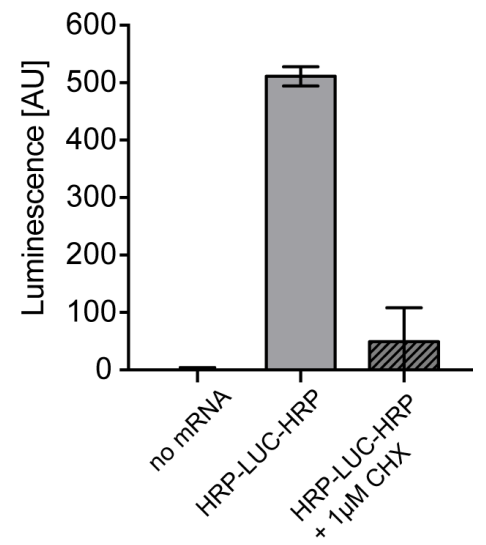

C

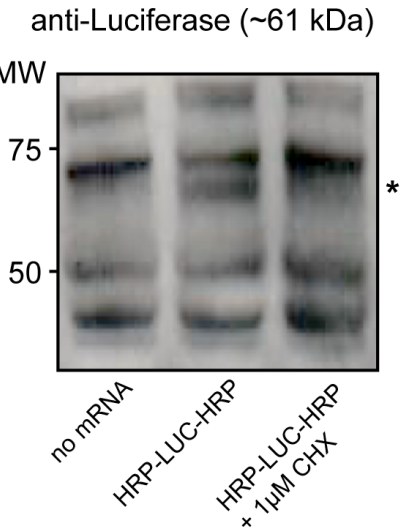

D

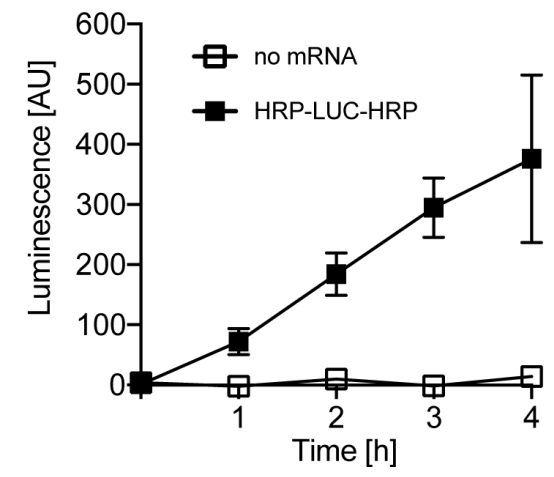


Baumann et al - Figure 2.

A

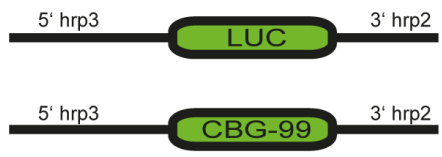

B

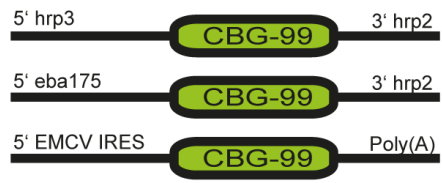

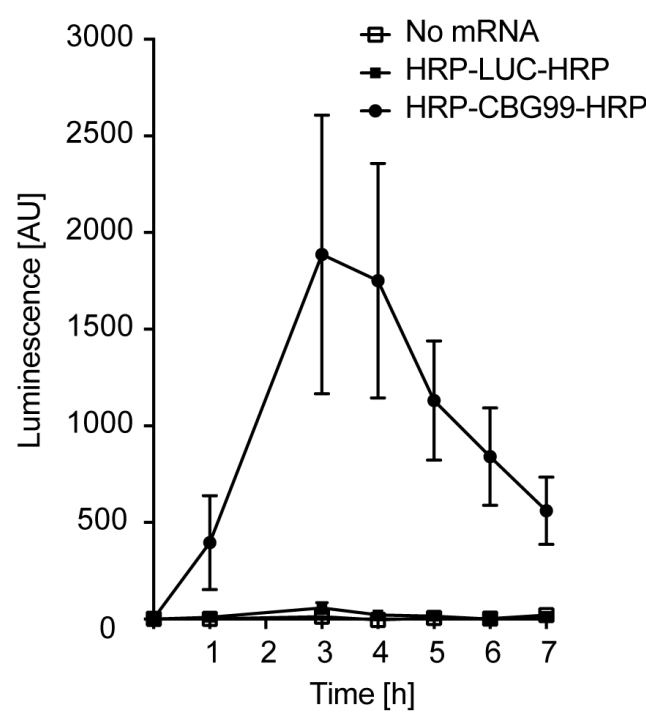

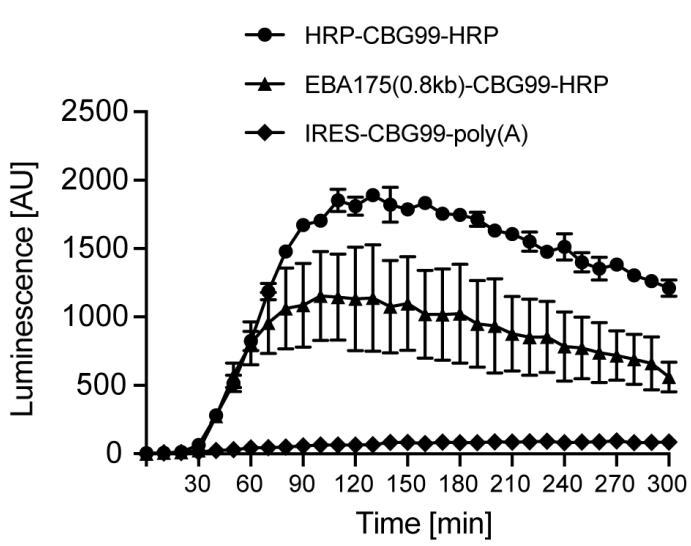


bioRxiv preprint doi: https://doi.org/10.1101/248740; this version posted January 16, 2018. The copyright holder for this preprint (which was not certified by peer review) is the author/funder, who has granted bioRxiv a license to display the preprint in perpetuity. It is made available under aCC-BY-NC-ND 4.0 International license.

Baumann et al - Figure 3.

A

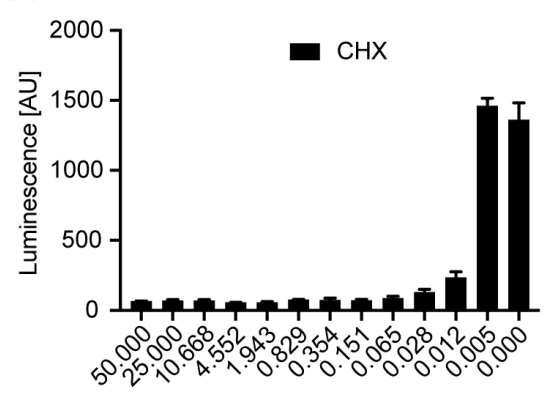

Concentration $[\mu \mathrm{M}]$
B

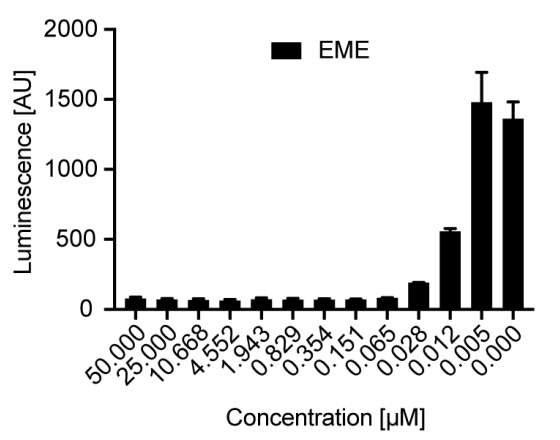

C

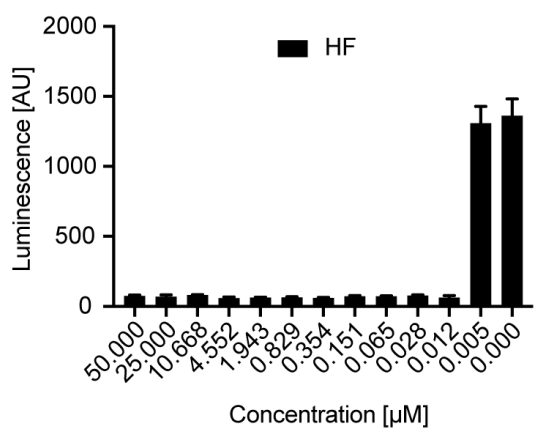

D

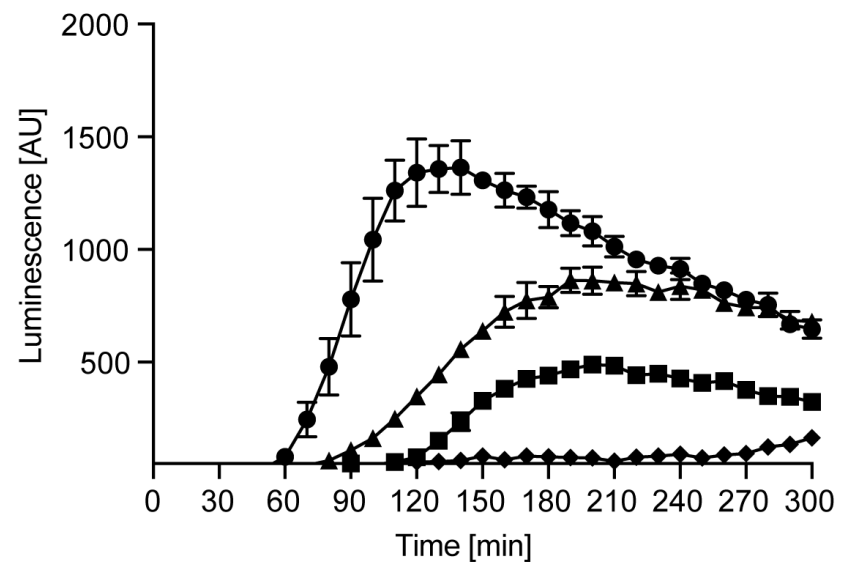

$\multimap$ HRP-CBG99-HRP

- HRP-CBG99-HRP

$+12 \mathrm{nM} \mathrm{CHX}$

\- HRP-CBG99-HRP

+12 nM EME

$\smile$ HRP-CBG99-HRP

$+12 \mathrm{nM} \mathrm{HF}$ 
Baumann et al - Figure 4.

A

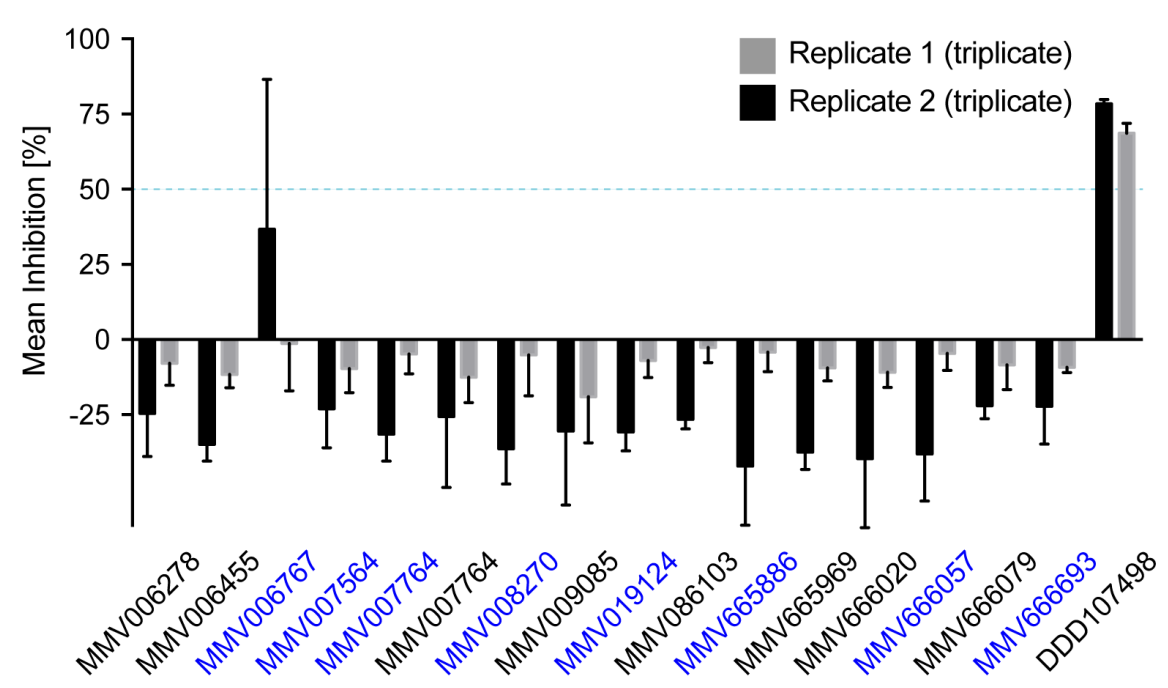

\section{B}

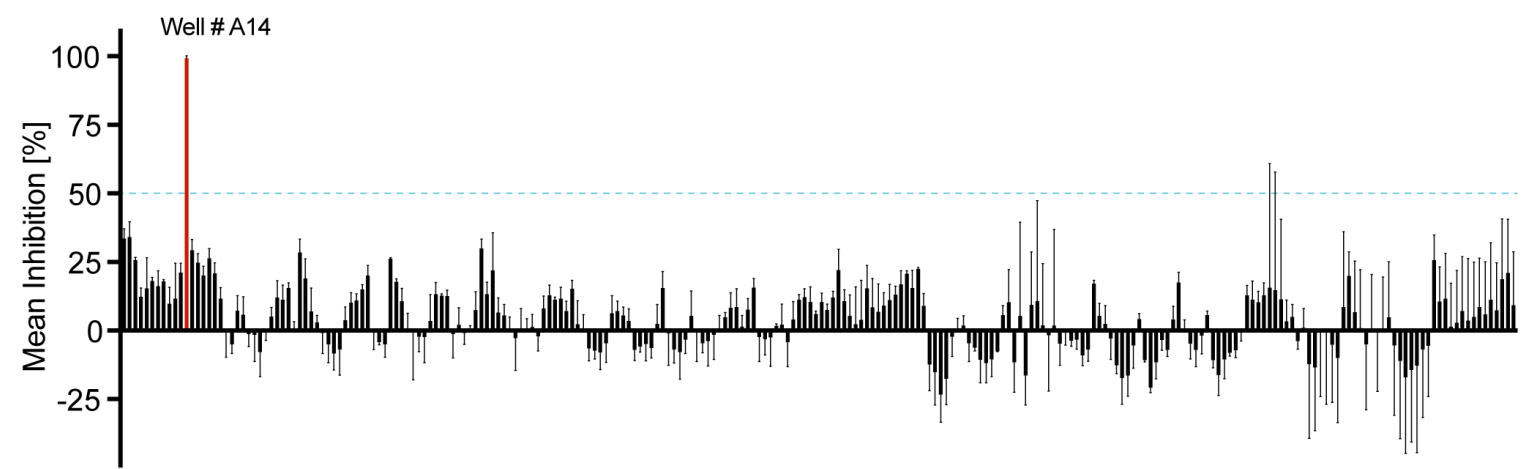

Well ID 